\title{
Erratum to: Speed optimization control method of smooth motion for high-speed CNC machine tools
}

\author{
Lin Wang • Jianfu Cao • Yuqiang Li
}

Published online: 1 December 2009

(C) Springer-Verlag London Limited 2009

Erratum to: Int J Adv Manuf Technol

DOI 10.1007/s00170-009-2383-2

Due to a processing error, the spelling of the author's names were incorrect.

The correct names should read Lin Wang, Jianfu Cao, Yuqiang Li doi.org/10.1007/s00170-009-2383-2.

L. Wang $(\bowtie) \cdot$ J. Cao $\cdot$ Y. Li

School of Electronics and Information Engineering,

Xi'an Jiaotong University,

Xi'an 710049, People's Republic of China

e-mail: wanglin_05@163.com 